\title{
Adenitis cervical con anaerobios sin causa aparente en lactante
}

\section{Cervical adenitis with anaerobes without apparent cause in infant}

\author{
Alejandra Arellano B. ${ }^{1}$
}

\section{Resumen}

Las adenopatías cervicales benignas en lactantes son relativamente frecuentes, se definen como el aumento de volumen ganglionar de más de $1 \mathrm{~cm}$, sin síntomas sistémicos y cuando están presentes, el término correcto es adenitis. Para su estudio, las adenitis se dividen en: locales, sistémicas, unilaterales, bilaterales, agudas, crónicas, y por edad, con diferentes etiologías. Se presenta el caso clínico de un lactante de 11 meses de edad con diagnóstico de adenitis cervical abscedada unilateral aguda, con cuadro de $72 \mathrm{~h}$ de evolución, con crecimiento constante a nivel cervical derecho, compromiso del estado general, fiebre y anorexia, por lo que se inician antibióticos de primera línea para los agentes bacterianos más frecuentes (Staphylococcus aureus y Streptococcus pyogenes), con evolución tórpida a las $48 \mathrm{~h}$, por lo que se solicita ultrasonido cervical, ya que la familia no contaba con recursos para solicitar cultivo o tomografía, reportando el ultrasonido ganglio cervical de $3,5 \mathrm{~cm}$ de diámetro abscedado, por lo que se agrega cobertura para anaerobios, con respuesta muy favorable a las $24 \mathrm{~h}$. Queda la duda del origen de los anaerobios en la paciente, sin antecedentes de importancia y en grupo etario diferente al afectado por esos gérmenes. Consideramos este caso interesante por su comportamiento atípico, para el enriquecimiento del ejercicio de la otorrinolaringología, recalcando el invaluable apoyo de la clínica y solo con un ultrasonido, ya que no siempre se tendrán todos los recursos disponibles, pero siguiendo las pautas de lo reportado en la literatura, se tuvo una resolución exitosa.

Palabras clave: adenomegalias, cervicales, adenitis, pediatría, anaerobios.

\begin{abstract}
Benign cervical lymphadenopathies in infants are relatively frequent, they are defined as an increase in lymph node volume of more than $1 \mathrm{~cm}$, without systemic symptoms, and when they are present, the correct term is adenitis. For its study, adenitis is divided into: local, systemic, unilateral, bilateral, acute, chronic, and by age, with different etiologies. An 11-month-old infant with a diagnosis of acute unilateral abscessed cervical adenitis, with a 72 hevolution, with constant growth at the right cervical level, fever and anorexia, for which first-line antibiotics were started to the most frequent bacterial agents (Staphylococcus aureus and Streptococcus pyogenes), with torpid evolution at $48 \mathrm{~h}$, for which only cervical ultrasound is requested, since the family did not have the resources to request culture or tomography, reporting the cervical ganglion ultrasound of $3.5 \mathrm{~cm}$ of abscessed diameter, so coverage for anaerobes is added, with a very favorable response at $24 \mathrm{hrs}$. There remains the doubt of the origin of the anaerobes in the patient, without important antecedents and in an age group different from that affected by these germs. We consider this case interesting due to its atypical behavior, for the enrichment of the otolaryngology exercise, emphasizing the invaluable support of the clinic, and only with an ultrasound, since other clinical tools were not available, but following the guidelines of what is reported in literature, there was a successful resolution.
\end{abstract}

Keywords: adenomegaly, cervical, adenitis, pediatrics, anaerobic.
'Otorrinolaringología y Cirugía de Cabeza y Cuello, Universidad Nacional Autónoma de México, C.U., Coyoacán, 04510. Ciudad de México, México.

La autora declara no tener conflictos de interés.

Recibido el 14 de octubre de 2020. Aceptado el 16 de marzo de 2021

Correspondencia: Alejandra Arellano B. Castillo de Buckingham 10, Sayavedra. Atizapán de Zaragoza, Estado de México CP 5293. Ciudad de México, México.

Email: alejandra_arella@ hotmail.com 


\section{Introducción}

El término adenopatía hace referencia a la alteración en el tamaño o consistencia de los ganglios linfáticos cervicales, por lo general benignas, definiéndose como el aumento de volumen ganglionar por encima de $1 \mathrm{~cm}^{1-3}$. Se calcula se presenta hasta en el 55\% de los menores que acuden a la consulta por otras causas, con localización principalmente en la región lateral del cuello ${ }^{4,5}$. Cuando aparecen datos de inflamación local y signos y síntomas sistémicos, el nombre correcto es adenitis ${ }^{6}$.

La causa principal de las adenitis en menores son infecciones virales de vías aéreas superiores seguidas de faringitis bacterianas, causadas principalmente por S. pyogenes y Staphylococcus aureus ${ }^{7}$, por lo que el manejo inicial para la etiología viral es sintomático y al sospecharse desarrollo bacteriano, se agrega una cefalosporina de segunda generación.

Presentamos el caso, de un lactante femenino con diagnóstico de adenitis cervical abscedada unilateral aguda, la cual en el momento de la consulta, presentaba 72 h de evolución, con crecimiento importante constante a nivel cervical derecho, además de compromiso del estado general, fiebre y anorexia, por lo que se decide manejo con antibioticoterapia estándary al continuar con evolución tórpida a las $48 \mathrm{~h}$, se revalora previa realización de ultrasonido cervical, y debido a los hallazgos, se agrega cobertura para anaerobios, con excelente evolución.

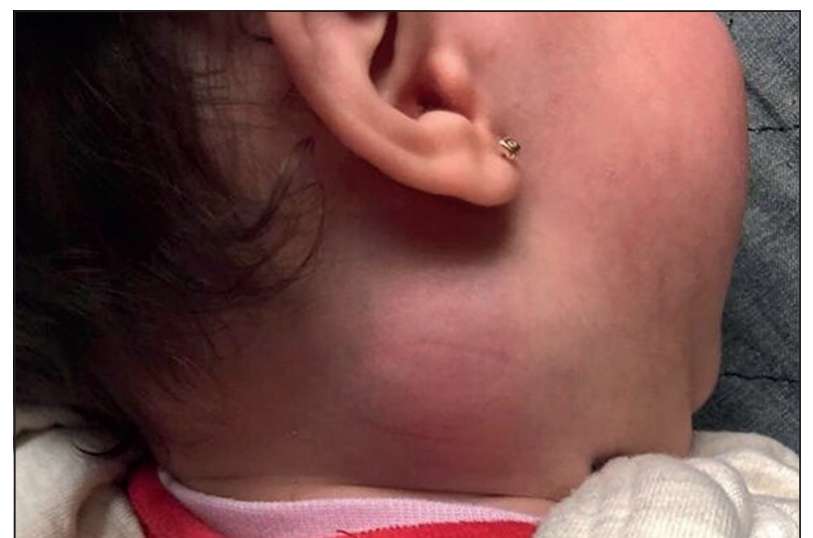

Figura 1. Aumento de volumen cervical derecho (nivel V, posterior al músculo esternocleidomastoideo y anterior al músculo trapecio), de $3 \mathrm{~cm}$ de diámetro aproximadamente, doloroso y duro a la palpación con hiperemia e hipertermia local.

\section{Caso Clínico}

Lactante femenino de 11 meses de edad, sin antecedentes familiares, personales, patológicos, ni perinatales de importancia. Gestación a término, peso y talla acorde a la edad cronológica, no infección de vías aéreas ni vacunación recientes, sin recibir vacuna de BCG hasta el momento, sin presencia de enfermedades concomitantes, sin ingesta de fármacos, lactancia materna durante 6 meses, actualmente sustituida por fórmula láctea, dentición iniciada, actualmente solo con presencia de incisivos centrales, sin contacto con mascotas, sin asistencia a guardería.

Inicia cuadro clínico con aumento importante de volumen en región cervical derecha, con hiperemia, hipertermia local y sistémica, dolorosa a la palpación, irritabilidad, anorexia, sin causa aparente, de tres días de evolución, por lo que buscan atención médica con pediatra, quién nos solicita interconsulta. A la exploración física, se evidencia lactante irritable, con aumento de volumen cervical derecho, de $3 \mathrm{~cm}$ de diámetro aproximadamente, dolorosa y dura a la palpación, hiperemia local, hipertermia local y sistémica, con crecimiento importante constante (Figura 1).

Se decide inicio de tratamiento con esquema sugerido en la literatura para el grupo etario, a base de cefuroxima $(20 \mathrm{mg} / \mathrm{kg} / \mathrm{día}$ en 2 dosis), y paracetamol ( $10 \mathrm{mg} / \mathrm{kg}$ cada 4 horas), con evolución tórpida dentro de las siguientes $48 \mathrm{~h}$ a la interconsulta, por lo que se realiza la revaloración del caso previa toma solo de ultrasonido cervical, debido a que los familiares no contaban con recursos para la realización de tomografía de cuello o cultivo, que reporta ganglio cervical de $3,5 \mathrm{~cm}$ de diámetro abscedado. Por los hallazgos se agrega al esquema inicial cobertura para anaerobios a base de metronidazol (40 mg/kg/día dividido en tres dosis), con mejoría franca a las $24 \mathrm{~h}$. Actualmente la paciente esta asintomática a tres meses del evento.

\section{Discusión}

Los ganglios linfáticos son un sitio importante para el inicio de la respuesta inmunitaria, se encuentran encapsulados y repartidos por 
todo el organismo, calculándose que existen entre 500 y 1.000 en el ser humano ${ }^{8}$. La infección de las vías respiratorias altas de origen viral seguidas por faringitis bacterianas causadas por S. pyogenes y Staphylococcus aureus son las causas más frecuentes de adenitis cervical aguda unilateral.

Las adenopatías de aparición subaguda o crónica se deben principalmente a micobacterias, enfermedad por arañazo de gato y toxoplasmosis. Las adenopatías generalizadas suelen estar causadas por una infección viral (mononucleosis infecciosa, rubéola o sarampión), y menos frecuentemente, por procesos malignos, enfermedades del colágeno o fár$\operatorname{macos}^{8}$.

En este caso particular, originalmente teníamos, al momento de la interconsulta, un lactante de 11 meses de edad, con diagnóstico de adenitis cervical unilateral aguda de $72 \mathrm{~h}$ de evolución, con crecimiento importante constante, además de compromiso del estado general, fiebre y anorexia, por lo que, con la sospecha de una etiología mixta, viral y bacteriana, se agrega esquema antimicrobiano de primera línea sugerido en la literatura internacional para el grupo etario y para los gérmenes habituales, con evolución tórpida a las $48 \mathrm{~h}$, por lo que se decide revaloración del caso con toma de ultrasonido cervical, que nos reporta ganglio cervical de $3,5 \mathrm{~cm}$ de diámetro abscedado, por lo que el diagnóstico se modifica a adenitis cervical abscedada unilateral aguda, y se agrega cobertura para anaerobios con metronidazol, según lo reportado en la literatura ${ }^{8}$ en relación a la frecuencia de agentes etiológicos involucrados, con respuesta muy favorable a las $24 \mathrm{~h}$. No fue necesario la realización de más estudios complementarios dado la buena evolución de la paciente, ni procedimiento quirúrgico alguno.

\section{Conclusión}

Por lo reportado en la literatura, los agentes etiológicos más frecuentes reportados en este grupo etario son en primer lugar virus seguidos de Streptococcus pyogenes ( $40 \%$ a $80 \%$ de los niños entre 1 a 4 años) y Staphylococcus aureus. En este caso, por la evolución progresiva, con compromiso del estado general, fiebre, anorexia y crecimiento importante de $72 \mathrm{~h}$ de evolución al momento de la interconsulta, se decide manejo antimicrobiano para los gérmenes más frecuentemente reportados y con el esquema sugerido en la literatura científica, indicando cefalosporina de segunda generación y analgésico.

Presenta evolución desfavorable a las 48 $h$, por lo que se revalora el caso con toma de ultrasonido cervical y al documentar datos de abscesificación se agrega cobertura para anaerobios, como se reporta en la literatura en relación a la frecuencia de los agentes etiológicos involucrados, con franca respuesta positiva, sin la realización de más estudios complementarios como tomografía o cultivo, dada la buena evolución de la paciente, y la falta de recursos económicos por la familia, también sin necesidad de realización de procedimiento quirúrgico alguno.

Sin embargo, llama la atención, la mejoría al agregar un fármaco con cobertura para anaerobios y la falta de algún antecedente claro en la paciente para el desarrollo de estos gérmenes, ya que sabemos que estos suelen aparecer en niños mayores de 5 años con patología dentaria ${ }^{8}$, lo que no corresponde con este caso. Por lo anterior, consideramos este caso clínico interesante, por su comportamiento atípico, para el enriquecimiento del ejercicio académico, recalcando el invaluable apoyo de la clínica y con solo un ultrasonido, ya que sabemos que no siempre se tendrán todos los recursos disponibles, y siguiendo las pautas de lo reportado en la literatura internacional, se tuvo una resolución exitosa.

\section{Bibliografía}

1. Darville T, Jacobs R. Lymphadenopathy lymphadenitis and lymphangitis. En: Pediatric Infectious Diseases. Philadelphia: WB Saunders, 2002;610-629.

2. Kliegman RM, Stanton BF. Nelson Textbook of Pediatrics 20a ed. Filadelfia Pensilvania Elsevier; 2016

3. Leung A, Robson W. Childhood cervical lymphadenopathy. J Pediatr Health Care. 2004;18(1):3-7. doi: 10.1016/j.pedhc.2003.08.008.

4. Gosche J, Vick L. Acute, subacute, and chronic cervical lymphadenitis in children. Semin Pediatr Surg. 2006;15: 99-106. doi: 10.1053/j. sempedsurg.2006.02.007. 


\section{CASO CLÍNICO}

5. Herzog LW. Prevalence of lymphadenopathy of the head and neck in infants and children. Clin Pediatr (Phila). 1983; 22: 485-7. doi: 10.1177/000992288302200703.

6. Swanson D. Etiology and clinical manifestations of cervical lymphadenitis in children. UpToDate, 2006 [en línea] www.uptodate.com

7. Tortora GJ, Derrickson B. Principios de Anatomía y Fisiología. 13. a ed. Panamericana; 2020.

8. Beléndez BC, Pérez-Morenob J, Saavedra LJ. Adenomegalias. Adenitis cervical. An Pediatr Contin. 2012;10(6);313-23. 